\title{
On the Role of Material Transfer in Friction Between Metals: Initial Phenomena and Effects of Roughness and Boundary Lubrication in Sliding Between Aluminium and Tool Steels
}

\author{
Viktoria Westlund $^{1} \cdot$ Jannica Heinrichs ${ }^{1} \cdot$ Staffan Jacobson $^{1}$ (D)
}

Received: 14 March 2018 / Accepted: 25 June 2018 / Published online: 30 June 2018

(c) The Author(s) 2018

\begin{abstract}
In the absence of a lubricant, the friction we measure in sliding contact between metals is typically high and quite erratic, with rapid fluctuations. If we filter out these rapid fluctuations, we can typically also notice slower trends, which can lead to quite dramatic friction changes. Unless careful studies are performed, the cause to this behaviour cannot be understood. How come a material couple cannot be characterised with a specific coefficient of friction? The present paper sets out to add understanding to this area, by conduction and analysing an experimental series involving sliding between a needle-like aluminium tip against tool steel flats. The load is high enough to cause substantial plastic deformation of the aluminium needle; its tip becomes formed by the contact against the tool steel. These small-scale, low sliding distance tests facilitate detailed studies of the initial stages of various friction trends, and the effects of initial surface roughness and shifts of this roughness caused by material transfer between the sliding surfaces. Specifically, the effects on the transfer and friction behaviour from presence or absence of a boundary lubricant film and atmospheric oxygen were studied. It was found that very smooth sliding surfaces can offer low-friction conditions for these metal types. However, the smooth sliding interface is very fragile. In all unlubricated cases tested, it very rapidly (in less than a few mm sliding) became ruined due to transfer, and the friction level correspondingly increased. The boundary lubricant could only offer low friction in cases where the flat steel surface was very smooth. The lubricant also facilitated smoothening of transferred aluminium. As long has been well known, boundary lubrication films typically do not totally hinder direct metallic contact in solid to solid contact. The present results strengthen this view and further suggests that in these direct contacts one of the major friction reducing effects of the lubricant is to efficiently limit transfer, which otherwise acts to make the sliding surface rough.
\end{abstract}

Keywords Friction $\cdot$ Roughness $\cdot$ Material transfer $\cdot$ Lubrication $\cdot$ Friction fundamentals

\section{Introduction}

The sliding friction between metals has an enormous impact on our modern technical world. If we were able to reduce the friction, or control it, or better understand how to lubricate it at low cost and without products with negative impact on environment or health, the benefits would be tremendous.

Despite its importance, but due to its complexity, the subject is still far from fully understood. The complexity is basically due to the very strong interaction between the opposing

Staffan Jacobson

Staffan.Jacobson@Angstrom.uu.se

1 The Ångström Laboratory, Tribomaterials Group, Uppsala University, Box 534, 75121 Uppsala, Sweden solid surfaces that occurs as soon as they are not separated by a lubricating film. In such spots of local direct contact, the pressure becomes very high and typically the softer surface will deform plastically. Further, atoms or larger parts will be transferred between the surfaces, oxidation or other chemical reactions will take place, the local topography will be modified, and so on. All such changes will modify the friction, often dramatically. They are also often hard to predict or control, and are influenced by many parameters.

The present investigation is intended to add a small piece to the big friction puzzle, by investigating the very initial phenomena occurring in sliding between an aluminium alloy and two tool steels. Only the first few millimetres of sliding are studied, and special emphasis is put on the relation between friction and transfer of material between the surfaces. Specifically, the effects of roughness, presence of 
lubricant and presence of oxygen, as in normal atmosphere or much reduced as in the scanning electron microscope (SEM), are investigated.

Although the results are thought to be relevant for many material systems and applications, especially those comprising dissimilar metals in sliding contact, our specific selection of materials and experimental parameters are primarily motivated by the cold forming application.

Reduction or elimination of lubricants in metal machining and metal forming is a hot topic. This is motivated by the cost reduction for both the lubricant and for its removal after the process. It is also often motivated by sustainability and human health issues [1,2]. A common problem in many forming operations is that material transferred from the work material to the tool damages the finish of the tool surface. This may lead to two serious problems: the transferred material lumps scratch the formed surfaces, and the transferred material leads to increased friction. This process, called galling, can eventually block the forming operation, so that the tool has to be replaced or reconditioned.

The transfer of material in sliding contact is far from a new subject. Already in the first classic book by Bowden and Tabor [3], the transfer between metals in lubricated and unlubricated sliding contact was carefully investigated; and the decisive effect of a good boundary lubricant in restricting the transfer and reducing the friction was demonstrated. Considerable effort has since then been devoted to increasing the general understanding of the role of transfer in friction and particularly on studying, predicting, delaying and ultimately preventing galling in industrial forming processes. Detecting galling at an early stage is important to reduce the production of scrap products and minimize material consumption. The use of acoustic emission has been suggested as a way to monitor galling in industrial applications [4]. It was demonstrated using a strip reduction test and showed promising results also for minor levels of galling. To understand the galling process, it is also important to recognize the early signs. In [5] the build up of a transfer layer is modelled from a single asperity contact. It is shown that the angle and geometry of the initial micrometer scale transfer particles are of importance for the subsequent growth of these particles. Heide et al. [6] studied the transfer material build up and friction development using a slider-on-sheet tribometer. They concluded that a low initial friction coefficient is not a guarantee for a good galling prevention. Karlsson et al. [7] used a similar test set up to study the different stages of galling and noted that the tool steel surface was worn by the substantially softer stainless steel sheet. The onset of galling was correlated to the proof stress of the sheet material and microstructure of the tool. In [8] Karlsson et al. further study the influence from tool steel microstructure on the galling tendency, and conclude that low loads caused transfer to protruding (hard phase) particles, when present, while lack of protrusions and/or high loads caused transfer also to the matrix. Their slightly protruding hard phase particles (only some $25 \mathrm{~nm}$ ) were concluded beneficial as long as they separate the tool steel matrix from the work material, but disadvantageous at high loads by causing mechanical interlocking of work material. While Karlsson et al. [7, 8] focused on the microstructure of very smoothly polished tool surfaces, Podgornik and Hogmark [9], Harlin et al. [10] and Schedin and Lehtinen [11] have turned the focus to the surface treatment of tools. Podgornik and Hogmark [9] conclude that a hard and smooth surface is important to reduce transfer and Harlin et al. [10] stress the importance of reducing surface defects in PVD coatings to avoid transfer and high friction. Both $[9,10]$ suggest the use of a WC/C coating to further improve anti-galling properties. Schedin and Lehtinen [11] made similar observations and reported that galling was initiated at defects in the surfaces. These defects could either be present already from the surface preparation, alternatively scratches or dents produced by e.g. transferred hardened sheet fragments during the sliding motion. This was more obvious when lubricant was omitted from the system, causing more sheet fragments roughening the tool surface. Chen and Rigney [12] utilised SEM and EDS to investigate the transfer processes between unlubricated metals in vacuum and concluded that transfer occurs by discrete particles during early stages of sliding. They also commonly observed two-way transfer, i.e. from metal A to B, as well as from B to A. Menezes et al. [13] investigated the influence from surface textures on galling (using a pin-on-plate sliding tester) and found out that although the influence from the texture on the friction level initially was high, it disappeared after just a few sliding cycles in the same track. Concurrently, also the differences in surface appearance were evened out, since transfer took place that hid the original texture. If lubricated, the surfaces were mainly scratched by the work material, which also eliminated the differences in texture after some sliding cycles. Another interesting observation in [13] was that iron from the hard tool surfaces was transferred to the much softer aluminium pin if unlubricated, while addition of lubricant strongly reduced this transfer.

Lubricant films are well known to strongly reduce the tendency to transfer between sliding metal surfaces, and are, therefore, commonly used to avoid such transfer in forming operations, etc. To pinpoint the influence of the lubricant on the transfer and wear behaviour similar tests have been performed with and without lubricant [11]. These tests generally showed that the same transfer and build-up mechanisms are active in both cases, however, the lubricant strongly delayed the transfer of work material to the tool and hence reduced the friction.

As indicated above, the material transfer potentially occurs already from the very onset of sliding. However, such very initial events are typically hard to detect especially in a real 
forming tool, but also in many types of sliding tests, e.g. when involving long sliding distances and large sample sizes. Rapid initial changes of the friction caused by rapid transfer events might be totally lost. The first friction values registered may be characteristic of a surface that has already been severely altered. To understand the rapid dynamics of friction under conditions that cause transfer, the very initial events must be captured. To facilitate this, tests combining a small localized contact, high resolution SEM and simultaneous friction measurements are suggested.

Aiming to investigate the very first sliding contact, and thus also the initial stages of material transfer between tool steels and softer metals, a series of micro-scale sliding tests have been performed in situ in the SEM [14-18]. The softer metals were selected based on that they are known to cause galling problems. The experimental set-up comprised tool material flats in sliding contact with small work materials tips. The load selected was high enough to plastically deform the softer tip, to represent the conditions of a work material against a forming tool.

The present study has employed the same in situ equipment and similar test design as in [14-18], but now complemented by corresponding tests made outside the SEM chamber, in air. To retain the ability of precision positioning of the sliding tip and some in situ observation capacity of surface damage and transfer, the tests in air were run while observed using a light optical microscope.

The tests in air serve several purposes. They facilitate lubricated tests, not possible in the SEM, and they provide a reference to the in situ tests with respect to the effect of the oxygen supply on the friction and transfer behaviour. Most metal surfaces are covered by a thin oxide layer in air. The rate of surface oxidation is associated to the partial pressure of oxygen; a low oxygen pressure results in a lower oxidation rate. In the SEM used in this study (Leo 440), the pressure is typically $1 \times 10^{-5}$ Torr, i.e. the oxygen partial pressure is around $10^{8}$ times lower than in the lab atmosphere. Even so, the time to form a monolayer of oxygen on an exposed metal surface would be less than a second [19].

Although lubricant films are commonly used in forming operations to avoid transfer, local or sporadic lubricant film loss is common and can lead to transfer. A special test scheme is designed here to study the capacity of a lubricant to restore damage or friction increases caused by such events. The scheme starts with unlubricated sliding of the tip to cause the transfer, then addition of an oil film and finally lubricated sliding of the tip over the same track, to evaluate the restoring effect of the lubricant.

\section{Experimental}

\subsection{Materials}

The tips were made from aluminium 6082, an industrially important alloy with magnesium and silicon as main alloying elements. This aluminium alloy is known for being hard to form by having a tendency to stick to the tools. The tips were cut out from sheet metal, turned and finally ground with 1000 grit followed by 4000 grit $\mathrm{SiC}$ paper, to achieve well-defined, sharp tips. The hardness of the alloy was measured to $113 \pm 2 \mathrm{HV}_{0.2}$.

Two tool steels were studied, a martensitic matrix steel grade with MC carbides (1-2 vol\%), produced by Uddeholms AB under the name Dievar, here called Matrix steel, and a powder metallurgy $(P M)$ steel grade, Uddeholms Vancron 40, here called $P M$ steel, consisting of a martensitic matrix with $\mathrm{M}_{6} \mathrm{C}$ carbides (5 vol\%) and $\mathrm{M}(\mathrm{C}, \mathrm{N})$ carbonitrides (19 vol\%) hard phases. The matrix steel has a hardness of $640 \pm 20 \mathrm{HV}_{3}$ and the PM steel $790 \pm 30 \mathrm{HV}_{3}$. Two Matrix steel flats were prepared to different surface topographies; the rougher was ground using 1200 grit SiC paper in the last step while the finer was polished using one micrometre diamond particles as the last polishing step. The PM steel flat was prepared in the same way as the smooth Matrix steel flat sample (Table 1).

\subsection{Sliding Tests in Air and in Situ in an SEM}

The test procedure was based on slow, short distance sliding of the aluminium tips against the polished or ground tool steel flats, see Fig. 1. The tips were spring loaded against the steel samples with a normal load of $3 \mathrm{~N}$. This load is enough to plastically deform the aluminium tip against the flat. During sliding the flattened plateau will grow to a diameter of $\sim 100-200 \mu \mathrm{m}$. In this way, the contact geometry rapidly turns into a flat on flat configuration, where the plateau area on the aluminium tip is several times larger than the area of real contact.

The tool steel sample was attached to a holder that was set into motion after loading the stationary tip, making

Table 1 Surface finish of the steel flats

\begin{tabular}{lc}
\hline Steel flat material & $\begin{array}{l}* \text { Average } \\
\text { Ra value } \\
{[\mathrm{nm}]}\end{array}$ \\
\hline Matrix steel, smooth & 5 \\
Matrix steel, rough & 170 \\
PM steel, smooth & 12 \\
\hline
\end{tabular}

*Average value of 5 measurements made with an optical profilometer (WYKO). Field of view 1, objective 50x, area measured $91 \times 120 \mu \mathrm{m}$ 


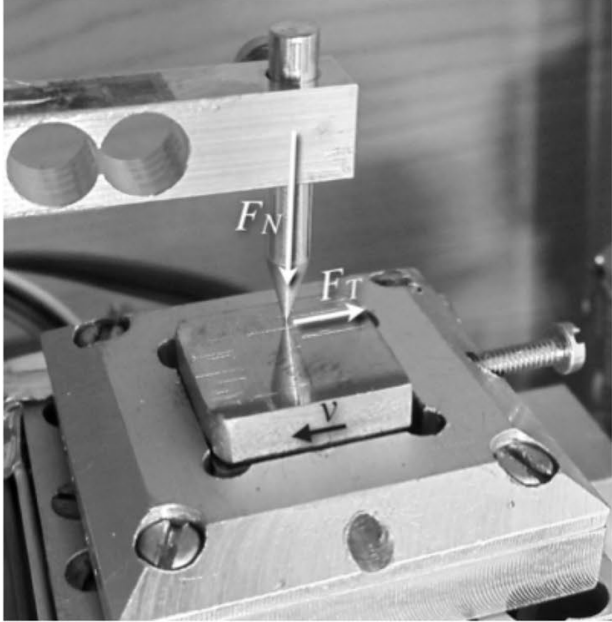

(a)

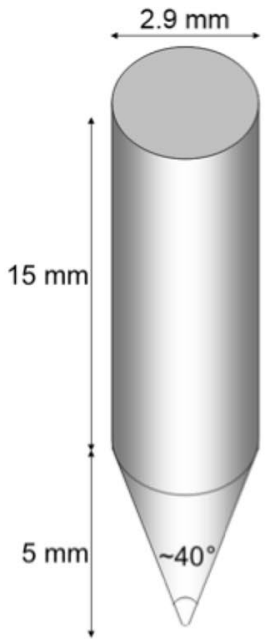

(b)

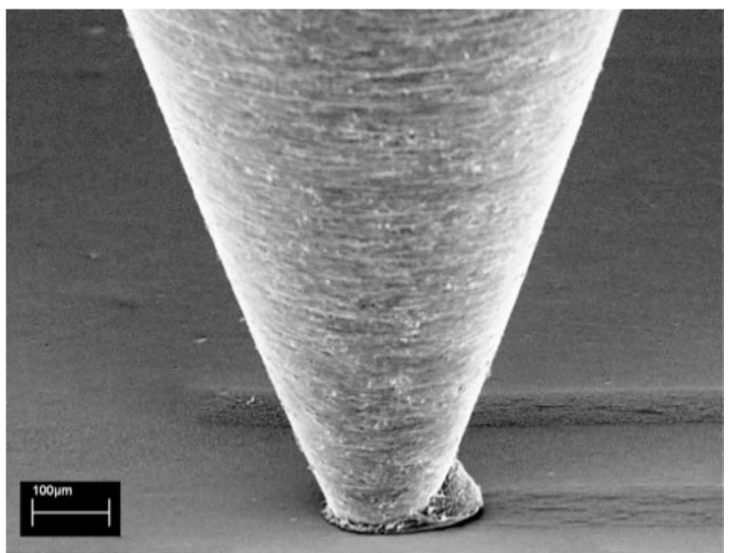

(c)
Fig. 1 Details of the present test. a The test set up with the needle like tip sliding over a polished flat under a load of $3 \mathrm{~N}$. The set up can be operated in situ in the SEM, or outside in air. b Schematic drawing of the aluminium tips. c Aluminium tip in sliding contact with a steel flat in the SEM. The tip is stationary while the flat sample moves to the right, and the contact has resulted in some transfer, leaving a visible track. The tip becomes flattened at first contact and then further deforms during sliding. High friction situations result in stronger contact area growth short tracks ( $2 \mathrm{~mm}$ long) over the surface. (The softer tips make limited damage to the steel, but are themselves severely deformed, and transfer to the steel surface is commonly found. The process can be compared to painting with a crayon on paper.) Multiple passages over the same area were performed by lifting the tip and moving the sample back to the start of the track. The sliding speed was around $2 \mathrm{~mm} / \mathrm{min}$. Before testing, all samples were cleaned $3+3 \mathrm{~min}$ in an ultrasonic bath, first in acetone and then in ethanol. By this cleaning procedure residues on the surface are minimized, but not completely absent. Low acceleration voltage SEM, which shows even very thin hydrocarbon films as dark shadows on the surface, was used to avoid scattered contaminated spots and to confirm that the actually tested areas were as clean as achievable without adding further cleaning procedures, such as plasma etching that can be performed within the vacuum chamber.

On the smooth Matrix steel flat, three tracks were made in air with 1,5 and 10 unlubricated passages, respectively, see

Table 2 The complete test matrix

\begin{tabular}{|c|c|c|c|c|c|c|}
\hline \multicolumn{6}{|l|}{ In air } & \multirow{3}{*}{$\begin{array}{l}\text { In SEM } \\
\text { Smooth steel flat } \\
\text { Matrix Steel + PM } \\
\text { Steel }\end{array}$} \\
\hline \multicolumn{3}{|l|}{ Smooth steel flat } & \multicolumn{3}{|l|}{ Rough steel flat } & \\
\hline $\begin{array}{l}\text { Matrix Steel + PM } \\
\text { Steel }\end{array}$ & Matrix Steel & Matrix Steel & Matrix Steel & Matrix Steel & Matrix Steel & \\
\hline Unlubricated & $\begin{array}{l}\text { Unlubri- } \\
\text { cated + Lubri- } \\
\text { cated }\end{array}$ & Lubricated & Unlubricated & $\begin{array}{l}\text { Unlubri- } \\
\text { cated + Lubri- } \\
\text { cated }\end{array}$ & Lubricated & Unlubricated \\
\hline $\begin{array}{l}3 \text { tracks; } 1,5 \text { and } \\
10 \text { passages }\end{array}$ & $\begin{array}{l}1 \text { track; } 10+10 \\
\text { passages }\end{array}$ & $\begin{array}{l}3 \text { tracks; } 1,5 \text { and } \\
10 \text { passages }\end{array}$ & $\begin{array}{l}3 \text { tracks; } 1,5 \text { and } \\
10 \text { passages }\end{array}$ & $\begin{array}{l}1 \text { track; } 10+10 \\
\text { passages }\end{array}$ & $\begin{array}{l}3 \text { tracks; } 1,5 \text { and } \\
10 \text { passages }\end{array}$ & $\begin{array}{l}3 \text { tracks; } 1,5 \text { and } 10 \\
\text { passages }\end{array}$ \\
\hline $\begin{array}{l}1 \text { and } 5 \text { passages: } \\
\text { tracks made with } \\
\text { the same Al-tip } \\
10 \text { passages: track } \\
\text { made with new } \\
\text { Al-tip }\end{array}$ & $\begin{array}{l}\text { All passages made } \\
\text { with the same } \\
\text { Al-tip }\end{array}$ & $\begin{array}{l}\text { All tracks made } \\
\text { with the same } \\
\text { Al-tip }\end{array}$ & $\begin{array}{l}1 \text { and } 5 \text { passages: } \\
\text { tracks made with } \\
\text { the same Al-tip } \\
10 \text { passages: track } \\
\text { made with new } \\
\text { Al-tip }\end{array}$ & $\begin{array}{l}\text { All passages made } \\
\text { with the same } \\
\text { Al-tip }\end{array}$ & $\begin{array}{l}\text { All tracks made } \\
\text { with the same } \\
\text { Al-tip }\end{array}$ & $\begin{array}{l}\text { All tracks made } \\
\text { with the same } \\
\text { Al-tip }\end{array}$ \\
\hline
\end{tabular}


Table 2. One aluminium tip was used for the tracks with 1 and 5 passages and a new one was used for the track with 10 passages. The tip was always shifted when shifting steel flat. Data on the number of passages the tips were used are given in Table 2. Three lubricated tracks were also made with 1 , 5 and 10 passages, respectively. A special sequence involving 10 unlubricated followed by 10 lubricated passages in the same track was also included, to study the capacity of a lubricant film to restore the friction level and surface finish of a surface that was first damaged by transfer during unlubricated contact. The smooth Matrix steel was also tested in an SEM, making three additional tracks, also with 1, 5 and 10 passages. The rougher Matrix steel flat was only tested in air. The same set of tracks and passages as for the smooth Matrix steel was applied.

The PM steel was tested following the same scheme, both in air and in situ in an SEM, while no lubricated tests were performed, see Table 2 .

The tests performed both in air and in situ in an SEM facilitate investigations of the effect of the air pressure - and specifically the corresponding oxygen level-on the friction and material transfer. The vacuum level in the SEM (Leo 440 ) is around $1 \times 10^{-5}$ Torr.

\subsection{Unlubricated and Lubricated Sliding Contact}

The sliding tests performed outside the SEM, in air, included both unlubricated and lubricated contacts. All unlubricated tests were performed first, to reduce contamination problems. For the subsequent lubricated tests, a thin film of PAO8 (poly-alpha-olefin), a synthetic unadditivated base oil with a kinematic viscosity of $8 \mathrm{cSt}$ at $100{ }^{\circ} \mathrm{C}$, was added to the steel flat. The film was formed by dripping a mixture of $6 \mathrm{wt} \%$ PAO8 in hexane on the surface and letting the hexane evaporate. This leaved lubricant films with a maximum thickness of $21 \mu \mathrm{m}$. The aluminium tips were changed between the unlubricated and lubricated tests. The only exception was the test scheme involving 10 unlubricated passages followed by 10 lubricated passages in the same track, where the same tip was kept for both situations.

\subsection{Friction Evaluation and Presentation}

The friction curve for each passage was acquired to allow correlation between friction changes and observed phenomena of material transfer, scratching, etc. Examples of complete friction curves are displayed in the results section. However, to allow comparisons between multiple tests, reduce clutter and clarify the friction level trends from the first to the tenth passage, most friction results are given using an alternative representation. These graphs show the average friction level of individual passages. To reduce scatter caused by problems to define the exact point for the onset of sliding, the average friction from 0.5 to $2 \mathrm{~mm}$ is presented.

\subsection{Pre- and Post-characterization of the Surfaces}

The surface damage and material transfer was studied in a FEG-SEM, using low acceleration voltage to make even very thin transfer layers visible. In some cases the samples were strongly tilted, to better visualize the topography. To allow studies of the tracks made in lubricated contact, the base oil was first removed by washing the steel sample in an ultrasonic bath with petroleum benzene, which efficiently dissolves oil. Elemental analysis was performed on all tips using Energy Dispersive X-ray Spectroscopy (EDS). To achieve surface sensitive analysis low acceleration voltages $(3 \mathrm{kV}$ or $5 \mathrm{kV}$ ) were used. Cross sections of selected aluminium tips were prepared using a focused ion beam (FIB) instrument.

\section{Results}

\subsection{Friction Between the Aluminium Tip and the Matrix Steel in Air}

\subsubsection{General Friction Observations for Unlubricated and Lubricated Contact in Air}

Typically, the friction level kept on relatively steady level during an individual passage, but this level sometimes shifted between the passages, as exemplified in Fig. 2. In some of the passages using an unused tip in a new track, the friction level initially showed a clearly shifting trend, as for the 1st passages in both Fig. $2 \mathrm{a}$ and b. That type of clear trends within a single passage was only found for the first passage over a track.

An alternative representation to clarify the friction level trends between passages from the first to the tenth passage is used in Fig. 3. From these it becomes clear that the lubricated friction slowly decreases with each passage, while the unlubricated sliding shows a less clear trend.

\subsubsection{Unlubricated Sliding Against the Smooth Matrix Steel in Air}

In the unlubricated tests on the smooth Matrix tool sample in air, the friction coefficient was initially relatively low $(\mu \approx 0.30)$ but almost doubled already during the first millimetre of sliding, see Fig. 2a. Since this is the first contact between a "virgin" tip over a "virgin" steel surface, the increase must be due to a change of the sliding surface of the aluminium tip. 

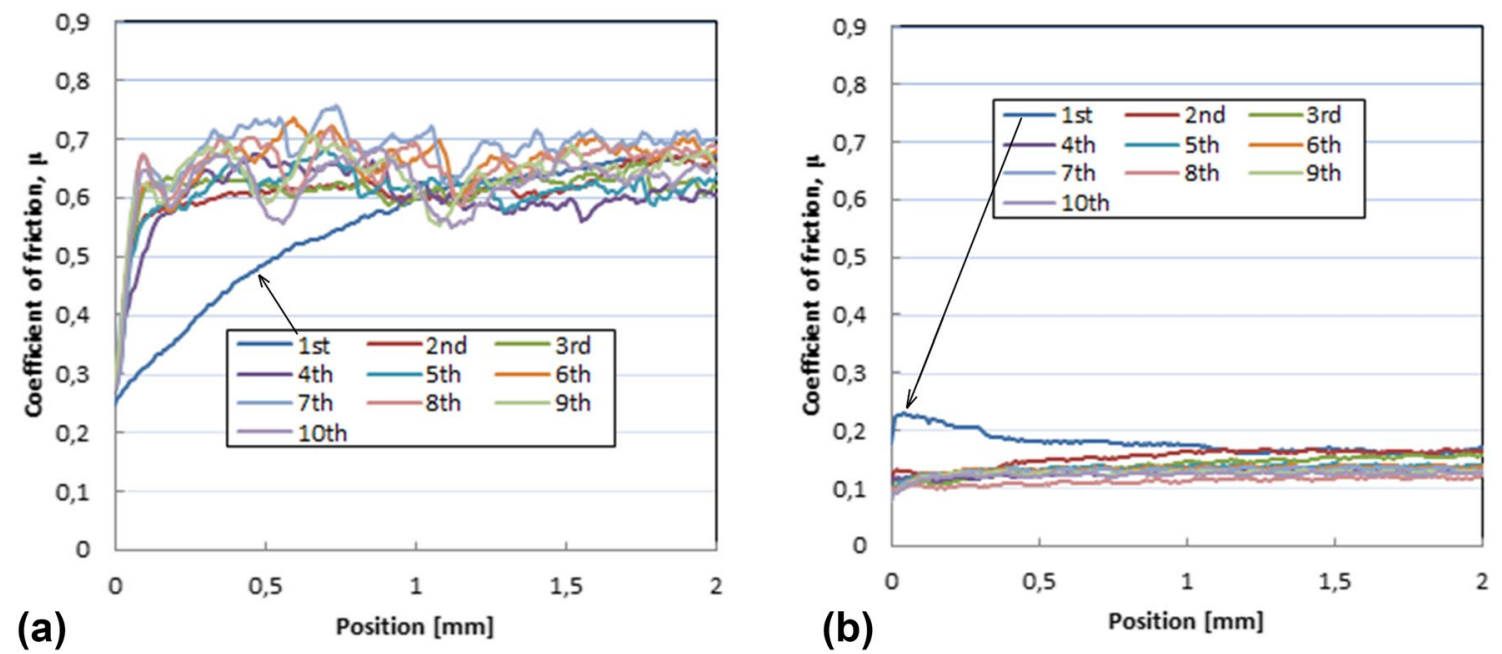

Fig. 2 Examples of actual friction curves for the aluminium tip slid against the smooth Matrix steel flat in air. a; 10 unlubricated passages, $\mathbf{b} ; 10$ lubricated passages

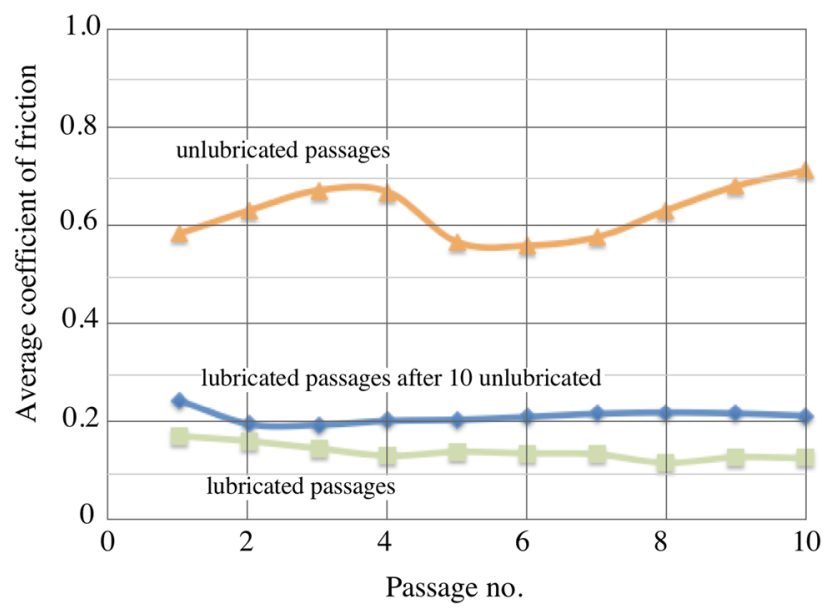

Fig. 3 Comparison of the unlubricated and lubricated friction between the aluminium tips and the smooth Matrix steel flat, in air. Development of the average friction levels from 1st to 10th passage. The results for the lubricated 10 passages over a track formed during 10 unlubricated passages are also included

The friction level then slowly fluctuates between passages, at around 0.65 . During these passages, aluminium becomes transferred to the tool steel, thereby making the sliding surface on the steel side rougher, as illustrated in Fig. 4. Moreover, the steel surface itself becomes roughened and scratched, as clearly shown in Fig. 5. After these 10 unlubricated passages in the same track, we can also note a thick oxide rich layer and within this substantial reverse transfer; i.e. iron has transferred from the tool steel to the aluminium tip (Figs. 6,7).

\subsubsection{Lubricated Sliding Against the Smooth Matrix Steel in Air}

Under lubricated conditions, i.e. with the thin PAO film pre-deposited on the steel surface, the friction coefficient gradually fell from 0.17 to 0.12 , over the 10 passages of the aluminium tip, see Fig. 3. Virtually no aluminium was transferred to the steel surface, see Fig. $4 \mathrm{~b}$.

When following 10 unlubricated passages by 10 lubricated passages in the same track, the friction level that had established at just above 0.7 during the unlubricated passages dropped to just over 0.2 already during the first lubricated passage, see Fig. 3. This initial level is just $40 \%$ higher than the friction in the lubricated tests that where not preceded by unlubricated sliding. The corresponding difference in surface appearance can be studied by comparing Fig. 4b, c.

A further comparison between the track formed during 10 unlubricated passages with that formed during 10 unlubricated +10 lubricated passages, shows that a clear majority of material that transferred during the unlubricated contact is still present, but that it has become smoothened, see Fig. 8 .

\subsubsection{Unlubricated and Lubricated Sliding Against the Rough Matrix Steel in Air}

Under unlubricated conditions, the friction against the rough Matrix steel surface was high already during the first passage. It then stayed in the range of $\mu \sim 0.5-0.6$ for the next eight passages before increasing to a value of just below 0.7 in the last passage (Fig. 9). A significant amount of aluminium was transferred to the steel surface during these passages (Fig. 10). 


\section{0 unlubricated passages}

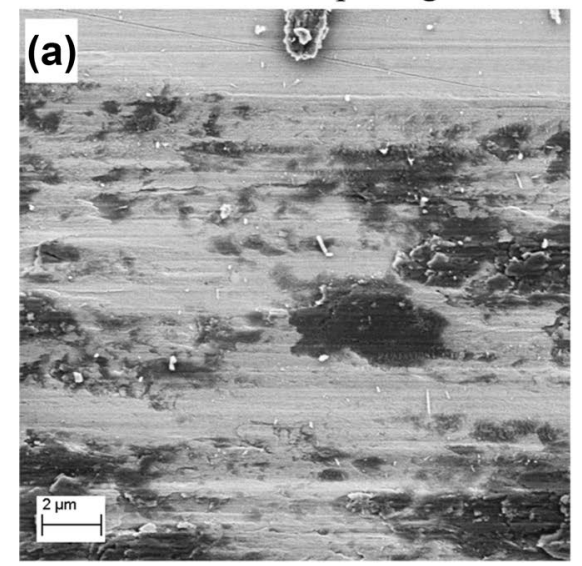

10 lubricated passages

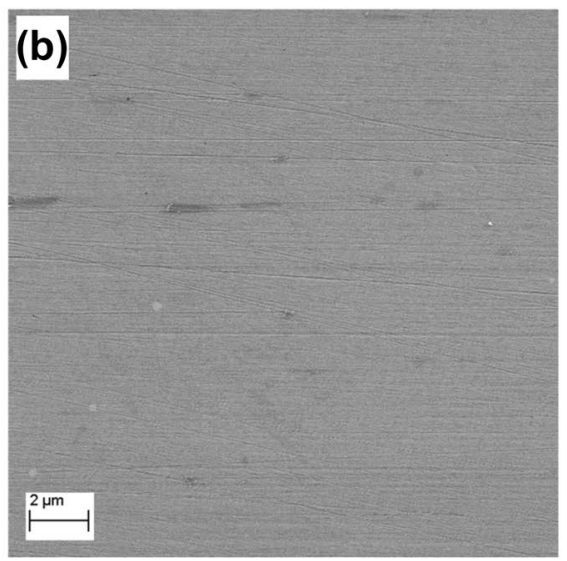

10 dry+10 lubricated passages

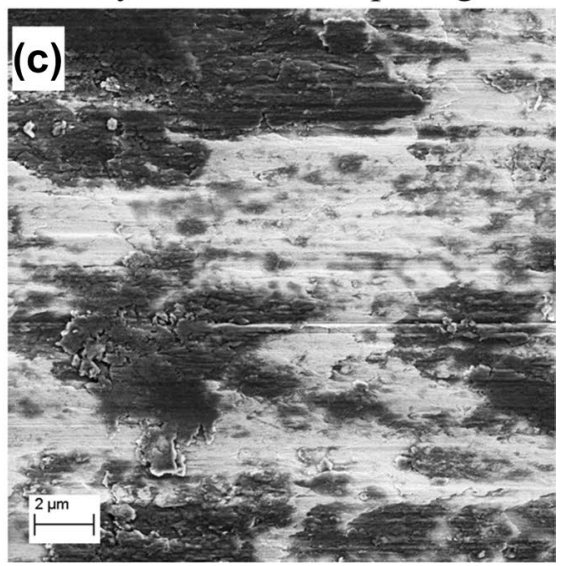

Fig. 4 Typical appearances of the sliding tracks on the smooth Matrix steel flats after 10 (or $10+10)$ passages of the aluminium tip. Sliding direction of the tip is from right to left

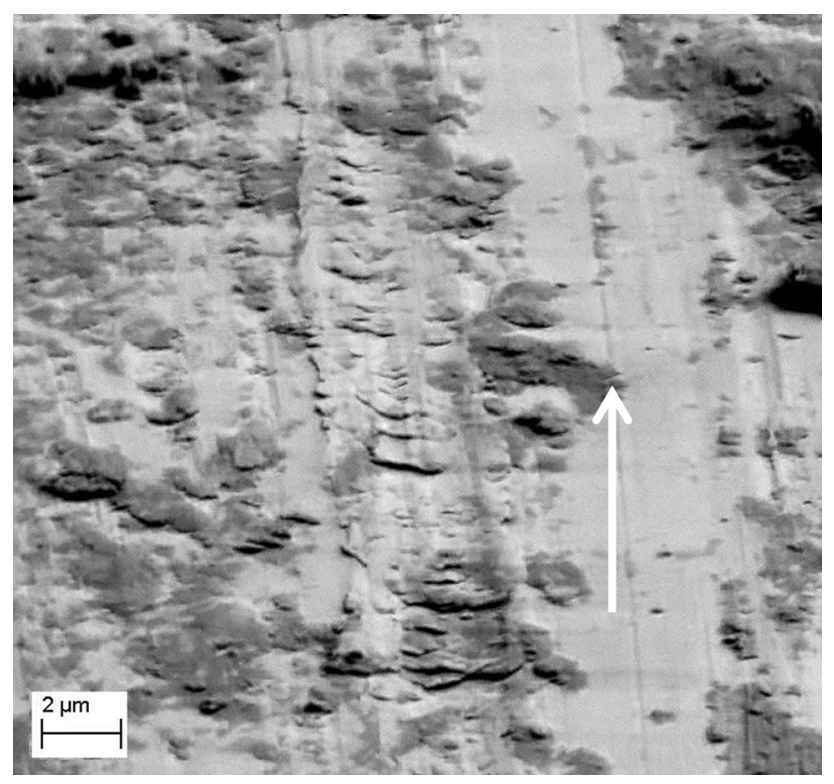

Fig. 5 Details of a scratch on the smooth Matrix steel flat after 10 unlubricated passages of the aluminium tip, in air. (Sample tilted $70^{\circ}$ to better reveal the topography). Sliding direction of the tip is indicated with an arrow

Under lubricated conditions the friction coefficient initially was just above 0.3 and then slowly decreased to levels around 0.25 (Fig. 9). Again, a substantial amount of aluminium was transferred to the rough steel surface, although the transferred material exhibited a smoother appearance than that transferred under the unlubricated condition (Fig. 10).

Already the first lubricated passage over the track initially formed during 10 unlubricated passages, showed a very low friction. The friction coefficient was only 0.2 , compared to almost 0.7 in the preceding unlubricated passage (Fig. 9).
Interestingly, this is substantially lower friction than measured in the lubricated runs (over the rough surface) not preceded by unlubricated runs. The friction then gradually increased and reached the level of the lubricated runs not preceded by unlubricated runs after some 5 passages. Then, both lubricated variants showed very similar friction levels. The amount of transferred aluminium did not change notably during these lubricated passages, but the transferred material became efficiently smoothened (compare Fig. 10d with Fig. 10f). This smoothening corresponds to the smoothening occurring with the smooth Matrix steel (Fig. 8).

\subsection{Friction Behaviour in Air Compared to that in Situ in the SEM}

The influence from the presence of oxygen was investigated for both steels (in smooth condition), by performing the same set of experiments both in air and in the SEM. The SEM does not allow testing under lubricated conditions, so for this comparison, only unlubricated conditions were included.

\subsubsection{Sliding Against the Smooth Matrix Steel}

For the smooth Matrix steel, the friction was significantly lower when the test was run in the SEM (with its much lower oxygen levels) than when run in air (Fig. 11). The first four passages showed a stable friction level close to 0.13 (as compared to around 0.6 in air). Here, the only deviation was the first few hundred microns of the first passage with the "virgin" tip surface, which showed higher friction. The following six passages showed a gradual friction increase.

The low friction level when run in the SEM corresponds to significantly less aluminium being transferred 


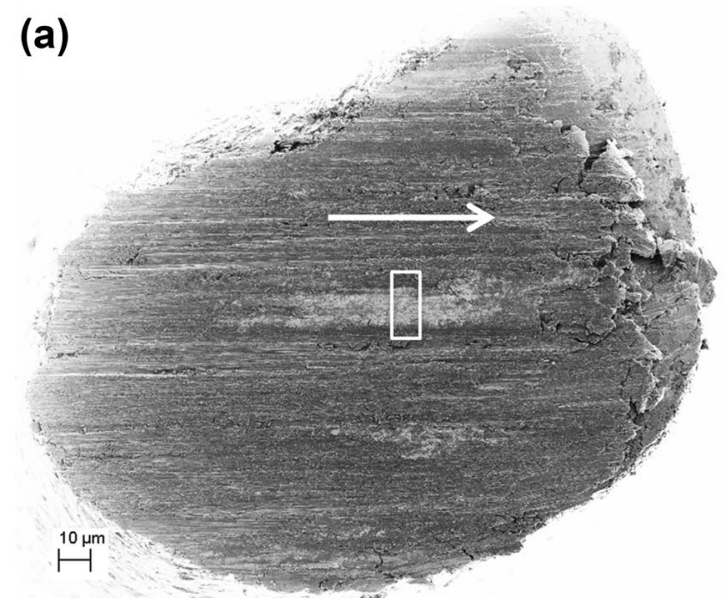

Fig. 6 The flattened end of aluminium tips slid against smooth matrix steel. a Tested in air. The light grey area is iron transferred from the tool steel. b Tested in the SEM. The lower friction level has led to

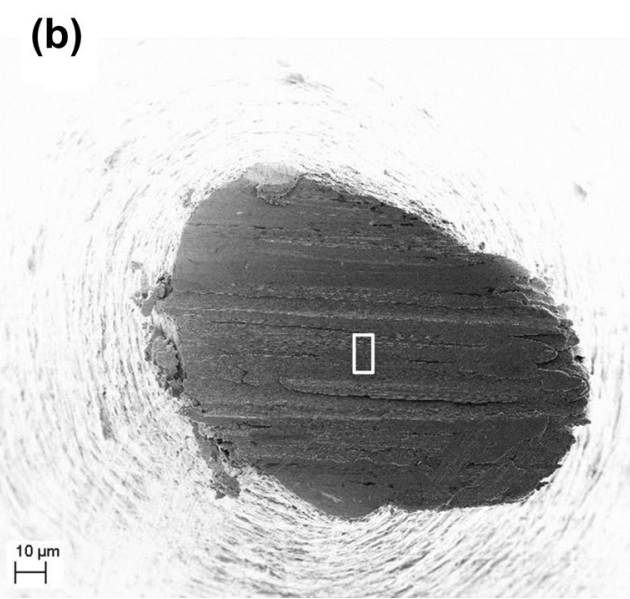

less severe plastic deformation. No transfer of iron detected. The arrow indicates the sliding direction of the opposing steel flat

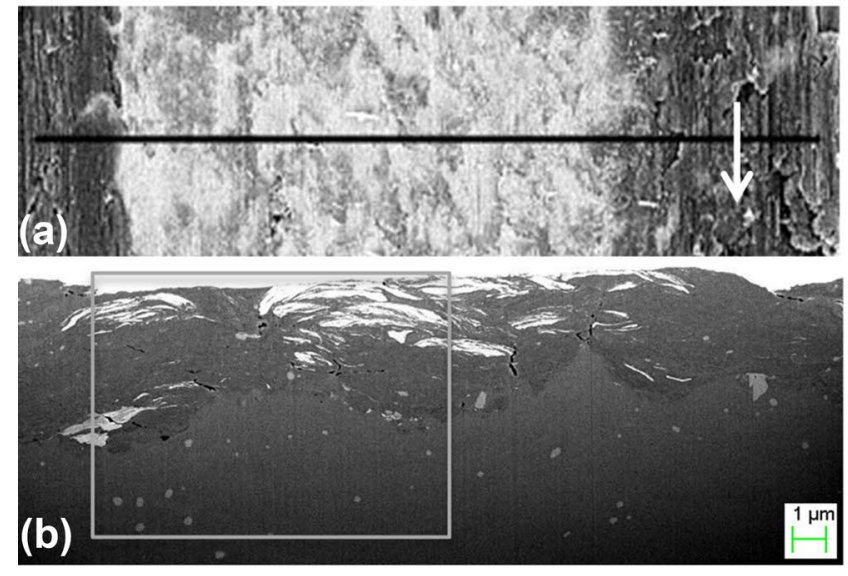

Al

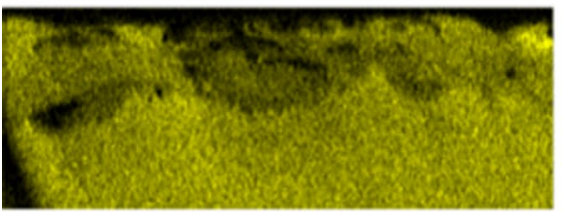

0

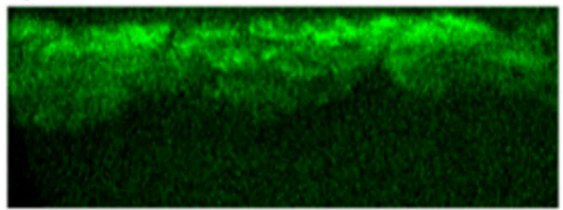

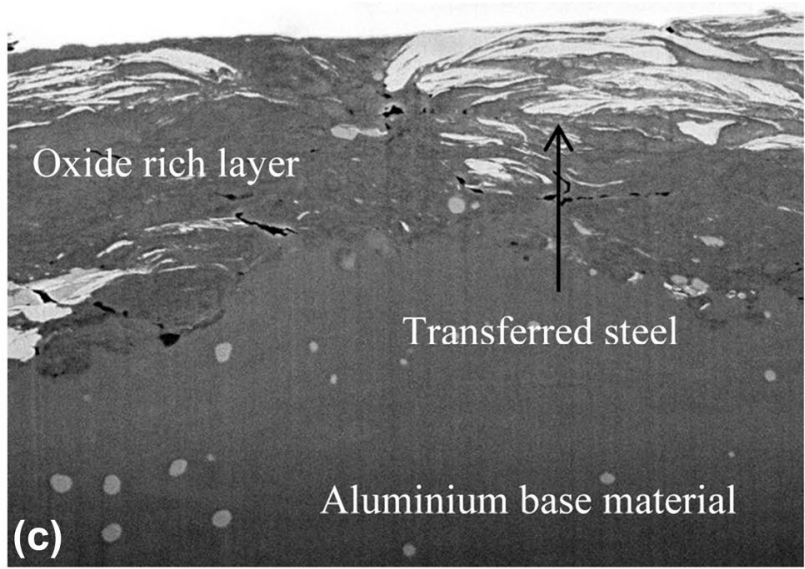

$\mathrm{Fe}$

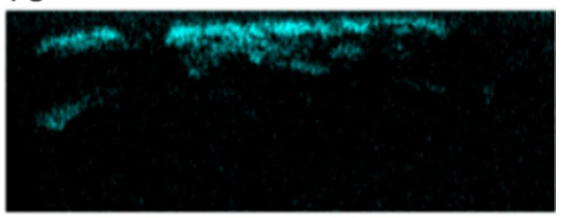

Fig. 7 Aluminium tip used for 10 passages in the same track over the unlubricated smooth Matrix steel in air (further analysis of framed area in Fig. 6a). a Surface at higher magnification, indicating sliding direction and FIB cross sectioning position. b, $\mathbf{c}$ FIB cross section at two magnifications. Sliding direction perpendicular to image

to the steel surface (Fig. 12). In contrast to when the tests were performed in air, the aluminium tip causes almost no scratching of the Matrix steel in the SEM. Further, no steel was transferred to the tip, and no oxide rich surface layer was formed, as illustrated in Fig. 13. (The lack of oxygen was verified by EDS, not shown here). plane. The white areas in images $\mathrm{a}, \mathrm{b}$ and $\mathrm{c}$ are steel transferred to the tip. The somewhat darker top layer embedding these steel particles is oxide rich. (The bright spots in the aluminium base material are particles rich in $\mathrm{Mg}$ and $\mathrm{Si}$.) The different layers have been identified using the EDS maps in the bottom row $(\mathrm{Al}, \mathrm{O}, \mathrm{Fe} ; 3 \mathrm{kV})$

\subsubsection{Sliding Against the Smooth PM Steel}

Unlubricated sliding against smooth PM steel in air resulted in a friction coefficient of 0.25 during the first passage, which then slowly increased during the subsequent nine passages (Fig. 11). After completing all ten passages, the 


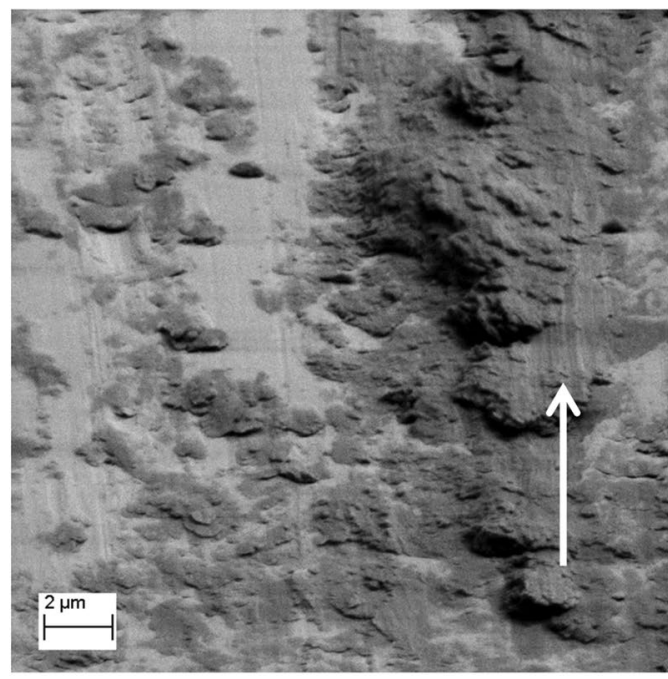

(a) 10 unlubricated passages

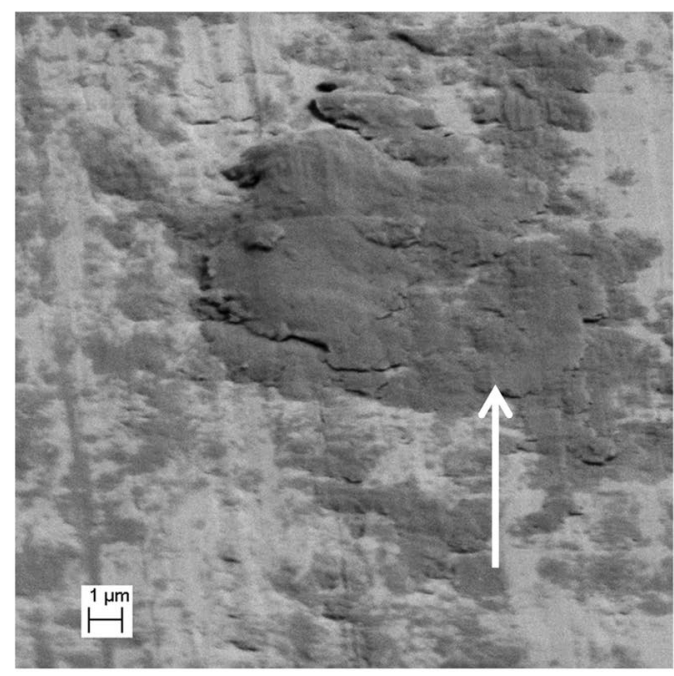

(b) 10 unlubricated +10 lubricated passages
Fig. 8 Typical appearances of the sliding tracks on the smooth Matrix steel after 10 passages of the aluminium tip in unlubricated contact (a), and after 10 unlubricated followed by 10 lubricated passages (b).

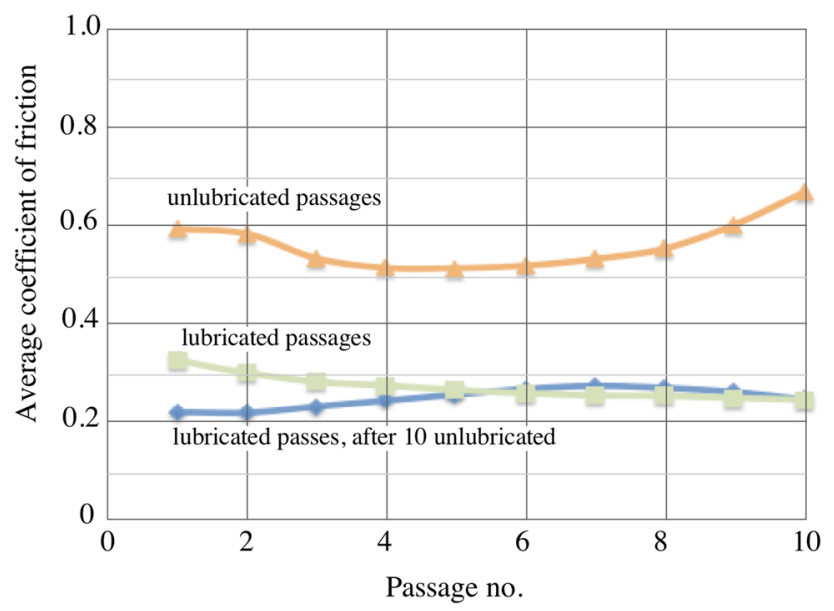

Fig. 9 Comparison of the unlubricated and lubricated friction between aluminium tips and the rough Matrix steel, in air. Development of the average friction levels from 1st to 10th passage. The results for the 10 lubricated passages over a track formed during 10 unlubricated passages are also included

smooth PM steel showed extensive aluminium transfer (Fig. 12). When performing the same test in the SEM, the friction levels were very similar. However, significantly less aluminium was transferred to the steel surface (compare Fig. $12 \mathrm{c}$ and Fig. 12 d). As clear from Fig. 12 d, the transfer that occurs is typically associated to carbonitride hardphase particles in the steel matrix.

Unlike the case of the unlubricated sliding against the Matrix steel in air, PM steel does not become scratched or roughened by the aluminium tip. Correspondingly, the
Views corresponding to Fig. 4 but with the samples tilted $70^{\circ}$ to better reveal the topography. Sliding direction of the tip indicated by arrows

sliding surface of the tip exhibited no signs of transferred steel, see Fig. 14 (the absence of Fe was verified by EDS, not shown here).

\section{Discussion}

The present results demonstrate that the relations between friction and transfer of materials between the sliding surfaces are complex, and strongly depend on the initial roughness of the tool material, the exact material composition, presence of oxygen and lubricants, etc. Low friction would ideally prevail when two smooth surfaces slide against each other, but there is a number of mechanisms that can ruin this smooth sliding.

\subsection{Requirements for Low Friction}

If we for now define low friction as $\mu<0.2$, we can see that in the present set of experiments this was only achieved in two cases: when the aluminium tip was run against the smooth Matrix steel either in the SEM or lubricated in air (Fig. 11, 3). The unlubricated sliding in the SEM initially gave the lowest friction, which then slowly escalated after the 4th passage. Contrastingly, the friction in lubricated sliding in air gradually decreased, to become the lowest after passage 5 .

The most apparent common denominator of these two cases is the smooth steel surface that is not immediately roughened by transferred aluminium, or by scratches. If such a situation is allowed to continue for some passages, the 


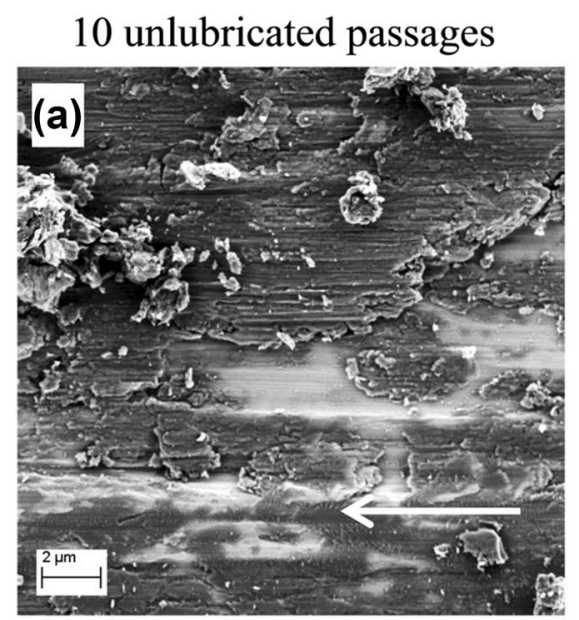

\section{0 lubricated passages}
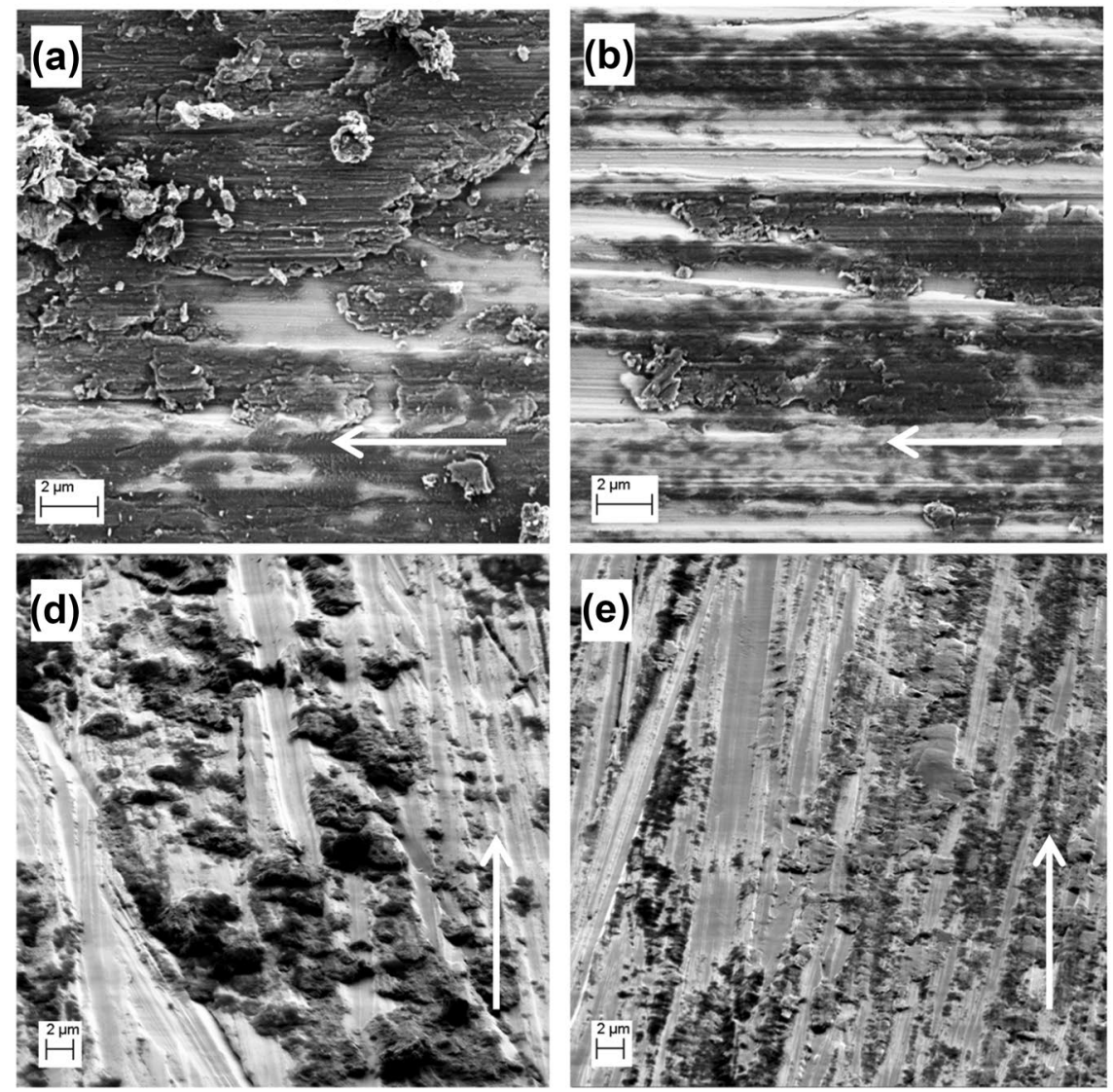

10 dry+10 lubricated passages
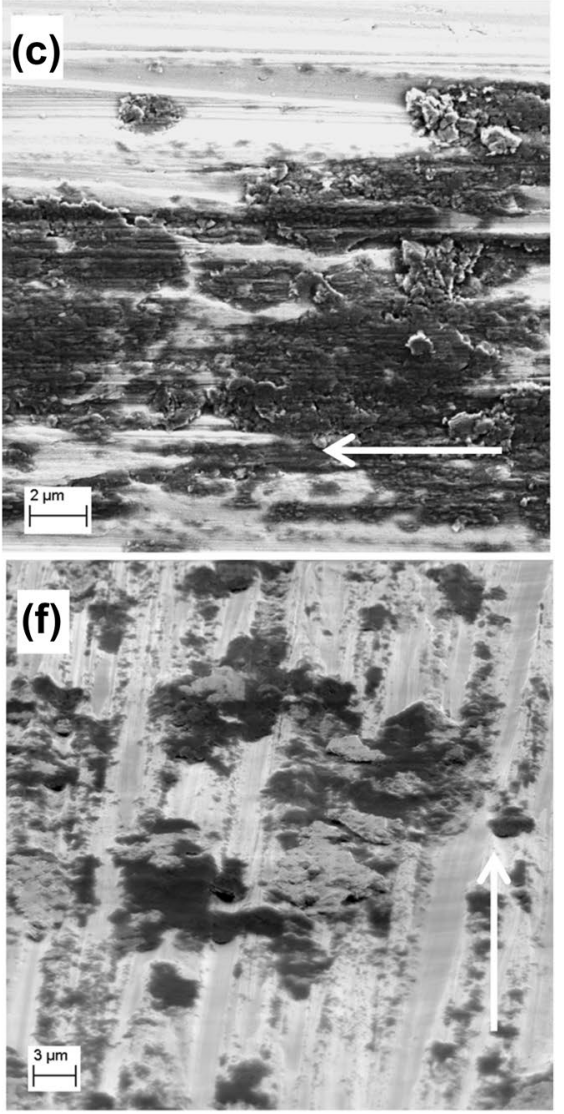

Fig. 10 The rough Matrix steel: a; after 10 unlubricated passages, b; after 10 lubricated passages and $\mathbf{c}$; after 10 unlubricated + 10 lubricated passages. Sample tilted $70^{\circ}$ in micrographs (d, e and $\left.\mathbf{f}\right)$ to better reveal the topography. Sliding direction of the tip indicated by arrows

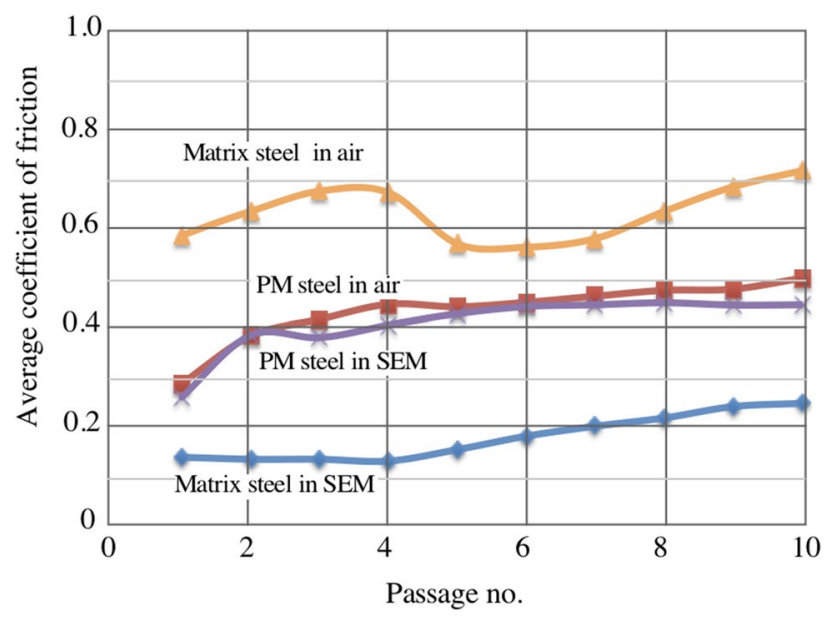

Fig. 11 Comparison of the influence from the atmosphere (as in air and in the SEM) on the unlubricated friction behaviour of the contact between aluminium tips and the smooth Matrix steel and the smooth PM steel. Development of the average friction levels from 1st to 10th passage surfaces may "self polish" to become even smoother. The softer aluminium surface may be effectively smoothened against the polished steel, and thin hardened surface layers may form. Smoother surfaces lead to lower local stresses and reduced deformation, which reduces the risk that boundary lubricant films (if available) become locally scraped off. All this reduces the rate of deformation during the continued sliding, and could, therefore, further reduce the friction.

If there are processes that gradually ruin the surface, such as small-scale transfer that slowly accumulates, the friction will escalate. When passing over the small-scale transfer, corresponding high local pressures and more severe deformation lead to larger scale transfer and roughening. Roughening leads to increasing ploughing friction and a less efficient boundary lubrication, and so on.

If we redefine low friction to $\mu \leq 0.25$, we can include 3 more cases; the smooth Matrix steel lubricated after initial unlubricated passages and the rough Matrix steel, both lubricated and lubricated after initial unlubricated passages. These three cases are characterised by all being lubricated, and all being dominated by sliding between 


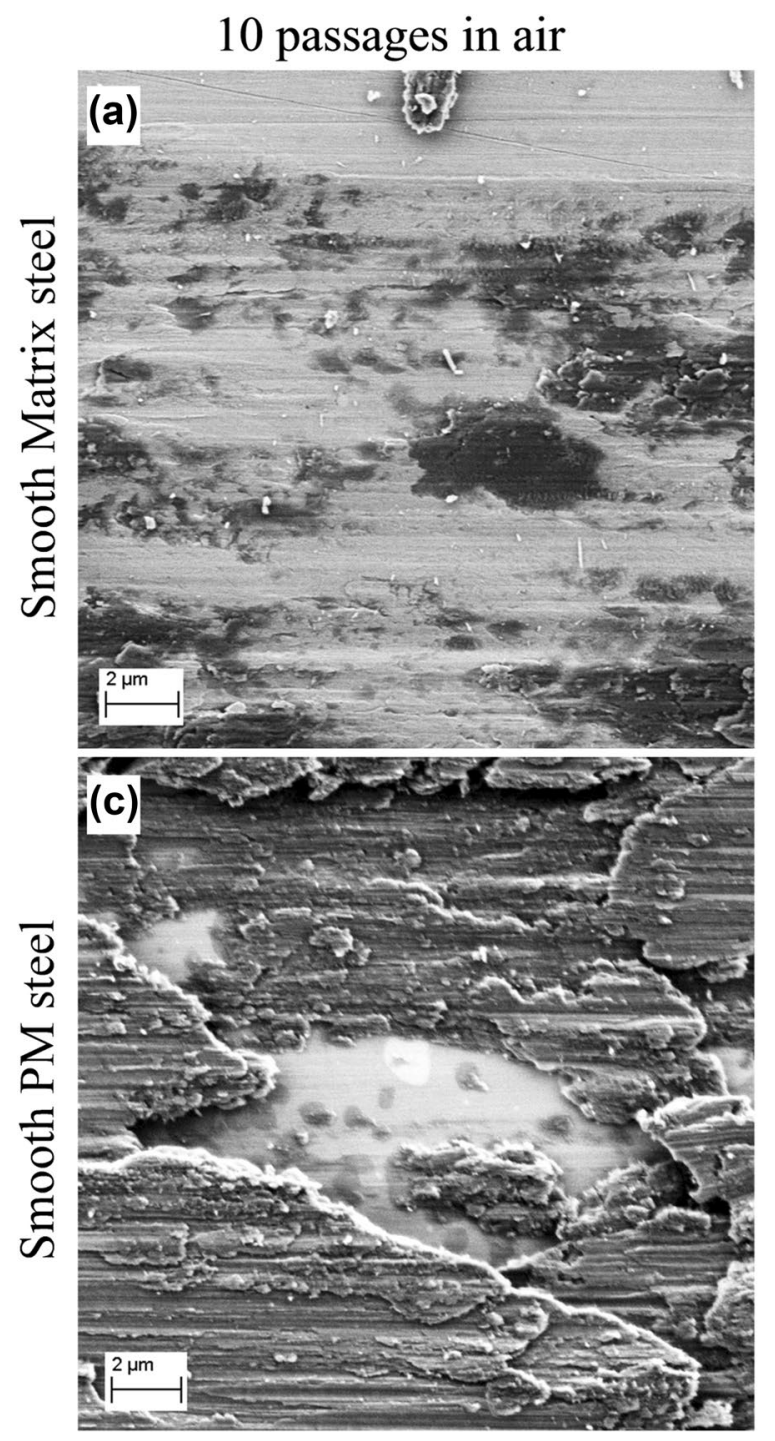

\section{0 passages in the SEM}
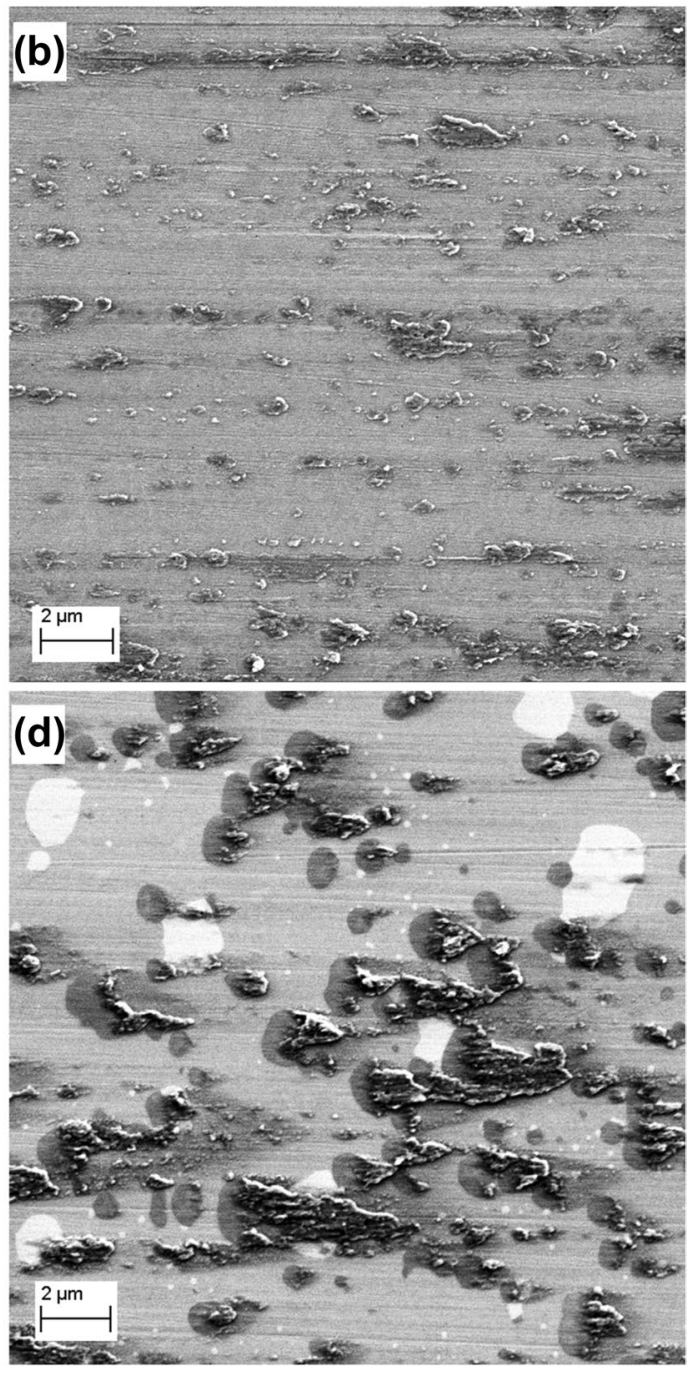

Fig. 12 Examples of surface appearances of the two smooth tool steels after 10 passages in air and in the SEM. The sliding direction of the aluminium tip is from right to left

the aluminium tip and transferred aluminium. Although the transferred aluminium became partially smoothened during the lubricated sliding in all three cases, the surfaces were still substantially rougher than the smooth version of the steel surface (Figs. 4, 10). For the lubricated rough Matrix steel it takes all 10 passages for the friction to fall from above 0.33 to 0.25 (Fig. 11). During these passages, transferred aluminium gradually fills out the grinding grooves, thereby gradually making the surface smoother. For the rough Matrix steel where the sliding track was first formed in unlubricated sliding, aluminium fills much of the grooves already at the first unlubricated passage and this process continues during the subsequent passages. Obviously, although this caused much deformation and high friction in the unlubricated condition, addition of the lubricant resulted in an immediate friction drop coinciding with smoothening of the most protruding parts of the surfaces.

\subsubsection{What is the Problem with Air for the Matrix Steel in Unlubricated Contact?}

The highest friction level was found for the unlubricated sliding between aluminium and the Matrix steel in air. For both the rough and the smooth surfaces, already the first passage showed a friction coefficient at around 0.6. This level, that has been reported as typical for unlubricated sliding of softer metals on harder [3], is four times higher than for the smooth Matrix steel in SEM and double the level of the $P M$ steel (in both SEM and air). If we look into the details, see Fig. 2a, the very initial friction is actually much lower. However, it shows a steady increase and reaches $\mu=0.6$ after 

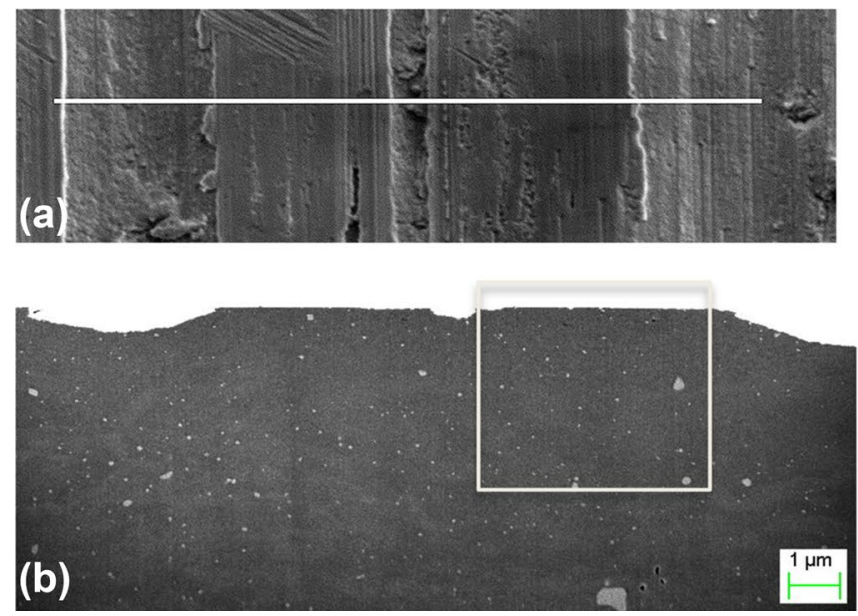

Fig. 13 Cross section micrographs of the aluminium tip after 10 passages in the same track over the unlubricated smooth Matrix steel in the SEM. Note the smooth sliding plateaus, and the absence of a thick oxide layer and transferred steel, as found on the corresponding tip run in air (Fig. 7). a Top view (framed area of Fig. 6b) with white

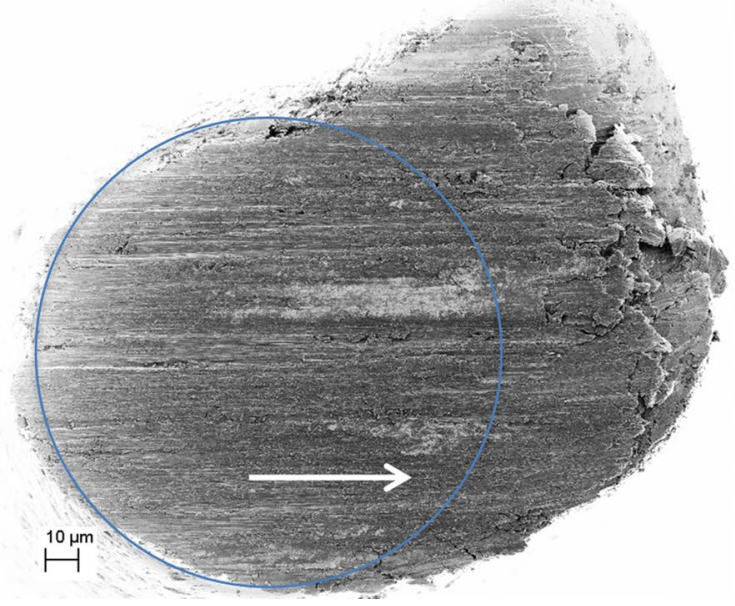

Fig. 14 Examples of the appearance of the sliding surface of aluminium tips after 10 unlubricated passages over a steel surface, in air. The originally quite circular shapes of the flattened tips have become severely deformed by shearing of a thin bottom layer in the sliding

about a millimetre of sliding. This special behaviour during the first passage with an unused tip was only noted for this case. (A very similar friction curve resulted when the test was repeated.)

As shown in Figs. 6 and 7, after all 10 passages the aluminium tip has become covered by a relatively thick heavily oxidised layer $(2-4 \mu \mathrm{m})$ that also includes steel fragments. Similar observations of transfer from the hard tool steel to the much softer aluminium have been made by e.g. Menezes et al. [13]. Further, despite much less capable microscopes, in fact transfer of steel fragments

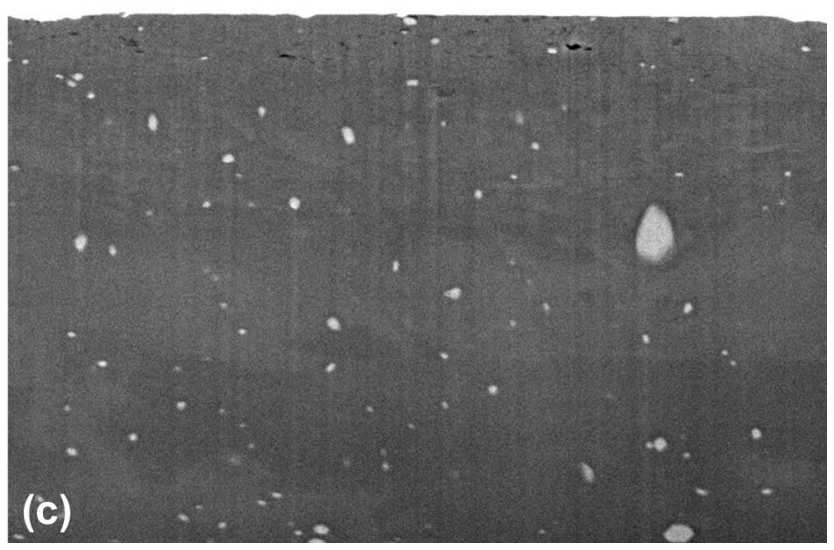

line indicating the positioning of the cross section. b Cross section overview. Sliding direction perpendicular to image plane. The small light spots in the aluminium bulk are particles rich in $\mathrm{Mg}$ and $\mathrm{Si}$. c Detail of b) illustrating the flat sliding plateau and the thin deformed layer with small pores

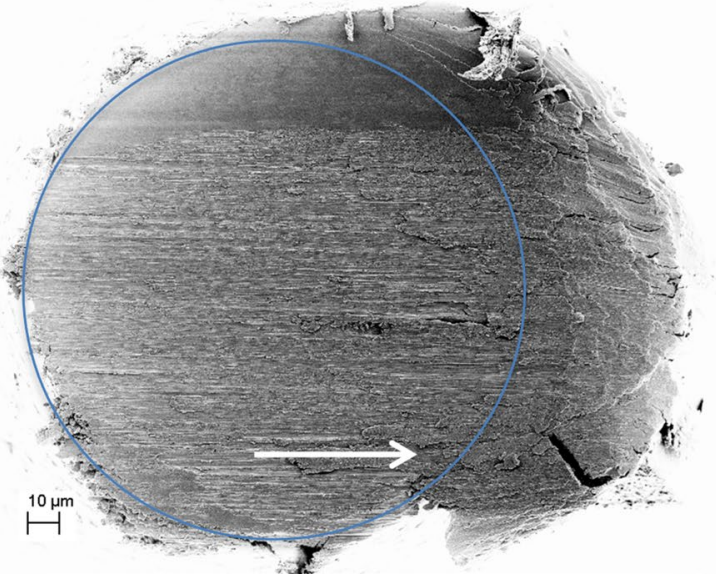

direction. Sliding direction of the counter surface is marked with arrows. Left; Slid against the smooth Matrix steel. Right; Slid against the smooth PM steel

to copper and concurrent sub-surface plastic deformation of the steel surface was reported already in the 1950s by Bowden \& Tabor [3]. In our present case, the thickness of the oxidised layer and its inclusion of steel fragments to several micrometres depth, indicates that the high friction is associated to severe deformation that causes whirl like mixing of the outermost layers. We suggest that this mixing repeatedly pulls down surface oxide, thereby forming a thick hard layer capable of wearing off steel particles. These steel particles also become mixed into the layer, and become a part of the strongly modified tip surface 
that is capable of scratching the hard tool steel. This layer formation is in strong contrast to the much gentler formation of smooth sliding plateaus, without noticeable oxide layers or transfer of steel, when the same test is conducted in the SEM (Fig. 13). Probably, the much lower oxygen content in the SEM limits the regeneration of alumina on the aluminium surface, as it becomes exposed due to the wear and mixing action. Thus, mixing of hard oxide into the surface layer will be much slower, and the sliding surface of the tip will not have the strength needed to wear off steel fragments.

\subsubsection{What Gives the Disadvantage of the PM Steel Compared with the Matrix Steel in SEM and What Gives its Advantage in Air?}

Although the investigated PM steel has a very smooth surface, much smoother than typical for forming tools, it causes substantial material transfer. In contrast to the Matrix steel, this happens both in the SEM and in air. The smooth Matrix steel causes very limited transfer of aluminium in the SEM. We can speculate that the aluminium tip slides with low shear stresses over the smooth Matrix steel surface, consisting mainly of iron oxide that is clearly softer than aluminium oxide, and that the tip also acts gently towards the steel, so that no steel is picked up.

However, the carbonitrides in the PM steel are very hard and slightly protruding from the surrounding matrix, and may further have some quite sharp nano-roughness (as was shown for the same material in [14]). Possibly these carbonitrides efficiently scrape off the native alumina layer from the tip, thereby exposing aluminium metal. This exposed aluminium is highly reactive, which leads to immediate transfer to the carbonitride surface. The first transferred aluminium will locally obstruct the sliding, thereby causing the formation of a larger irregular bump in front of the carbonitride. On the following passages, the transferred bumps will cause more transfer (denoted secondary transfer in [15]), and increased friction. When the test is performed in air, almost the entire sliding track is covered after 5 passages, while the transferred patches grow substantially less in the SEM, as was shown in Fig. 12. Although the transferred aluminium is not fully covering when testing in the SEM, it covers enough area to carry the whole load, i.e. the tip will not be in direct contact with the underlying steel. The similarity in friction development when run in air and in SEM (Fig. 11) suggests that - despite the different degree of coveragethe character of the contact interface (both roughness and material compositions) is very similar between the two cases.
We have no clear understanding about the mechanisms that cause this very similar friction behaviour in air and in the SEM, combined with such a wide difference in coverage of transferred material.

\subsection{Comparisons Between Unlubricated and Lubricated Contact in Air}

When testing the lubricated smooth Matrix steel flat (in air), the friction level stays low and actually slowly decreases, as shown in Fig. 3. This coincides with the steel surface staying smooth, rather than becoming roughened by scratching or transfer. In this test, the boundary lubricant film helps keeping the shear stresses low, which promotes an efficient flattening of the tip surface against the smooth steel flat. Probably this acts to avoid high local pressures, thereby almost eliminating further plastic deformation of the aluminium tip. The oxide on its surface then keeps intact, so that transfer is avoided and the friction can stay low.

Under the same lubricated conditions, the rough Matrix steel flat shows almost twice as high friction, as shown in Fig. 9. This is probably caused by that in the contact against the sharper ridge structures of the rough surface ( $\mathrm{Ra}$ $0.17 \mu \mathrm{m}$ ), the high local pressures will lead to deformation that cause scraping off of aluminium. (The thin boundary film cannot improve these situations of intense local pressure and plastic deformation.) The transferred aluminium mostly land in the grooves between the ridges. As the grooves become partly filled, the transferred aluminium can carry a part of the load, and acts to smoothen the rough steel surface. The boundary film now facilitates the smoothing of the transferred aluminium by reducing the local interfacial shear stress, and by counteracting continued transfer.

When testing the smooth Matrix steel flats in air without a lubricant, Fig. 3, friction reaches a high level (similar to that of the rough Matrix steel Fig. 9), coinciding with the originally smooth steel surface rapidly becoming very rough. This roughening is caused both by transferred aluminium and by scratches in the steel surface. The aluminium tip itself cannot scratch the steel surface, but the scratches are caused by the steel fragments that have become transferred and integrated into the tip surface.

When adding the lubricant to the steel flats that were first tested without lubricant, the friction level is drastically reduced from the very onset of sliding, for both the smooth and rough Matrix steel. The friction level then rapidly falls during the first millimetre or so, and then becomes relatively stable. For the smooth Matrix steel, it stayed on that same level for all the consecutive passages. The rapid change during the first passage indicates a change of the tip surface (a change in the track on the flat can not give an influence during a passage, only from one passage to the other.) The small reduction between passage 1 and 2 on the smooth Matrix 
steel is probably caused by a smoothening of the aluminium lumps that became transferred during the unlubricated passages. The stable level from passage 2 to 10 indicates that not much happens to the surfaces; not much transfer, not much smoothening. Boundary lubricated sliding takes place on top of the smoothened plateaus on the transferred aluminium.

\section{Conclusions}

The very initial tribological processes in sliding contact between an aluminium alloy and two tool steels have been investigated in a small-scale test. The test set-up involves a needle-like aluminium pin that has been sliding against steel flats, at low speed. The load has been high enough to immediately flatten the aluminium tip against the harder tool steel flat.

The friction level between aluminium and tool steel was shown to depend on a complex set of mechanisms, also under these very simplified and well-controlled conditions.

It was found that low-friction sliding was consistently associated to smooth sliding surfaces.

- On the hard steel flat this requires that the surface is initially smooth, and that it is not subsequently ruined by transferred aluminium or scratching.

- The much softer tip surface may initially be rough, since smooth plateaus form on the tip when it slides over a smooth flat under low-friction conditions.

- The stability of the smooth surfaces is promoted by lubrication.

- In the case of the smooth Matrix steel, the stability of the smooth surfaces is promoted by the absence of oxygen. This is probably due to a strongly reduced growth of an oxide layer on the aluminium side, which reduces the ability of the tip to damage the steel flat.

- On the smooth Matrix steel the coefficient of friction is actually a bit lower when tested unlubricated in the SEM, than when tested lubricated in air. However, the ranking soon shifts since the SEM vacuum (absence of oxide growth) seems less efficient than the oil film in preventing transfer of aluminium to the steel surface.

- The stability of the smooth surfaces is demoted by conditions that cause transfer from the aluminium tip to the steel surface, such as unlubricated sliding in air.

- The smooth sliding interface will not form (within this very limited sliding distance) when the harder surface initially is rough (roughness in micrometre scale).

- The formation of a stable sliding surface on the aluminium tip is also hindered by the carbides and carbonitrides in the otherwise very smooth PM steel surface. Although these hard phases protrude only a few nanometres, they cause transfer from the aluminium tip. This transferred aluminium protrudes much more than the original hard phases, causes secondary transfer and thereby hinder the formation of a stable smooth sliding surface also on the tip side. In this case, roughness on the nanometre scale (which on the first passage give $\mu=0.25$ ) leads to roughness on the micrometre scale, and $\mu \approx 0.45$.

- It is not necessary that the entire surface is smooth, but it has to be smooth over the areas that actually come into sliding contact. Such smooth sliding plateaus must, therefore, be larger than the required area of real contact, as determined by the load and the hardness of the softer material in contact.

- Transfer rapidly leads to modification of the contact from aluminium against steel into aluminium against aluminium (or their respective oxides).

Rough surfaces may "heal", i.e. become smoother and allow unobstructed sliding, in at least two ways:

- Smooth plateaus form on the rough aluminium transferred to the steel when lubricant is added to the contact. This occurs on both the rough and the smooth steel flats. Thus, the roughening caused during a temporary loss of lubrication is partly repaired by renewed lubrication.

- Transferred aluminium may fill out depressions such as grinding marks, thereby flattening the surface.

In both cases the friction level decreased as the surfaces became smoother.

In short Very smooth sliding surfaces may offer low-friction conditions for these metal types. However, the smooth sliding interface is very fragile. In all unlubricated cases tested, it very rapidly (in less than a few mm sliding) became ruined due to transfer, and in some cases also due to scratching, and the friction level correspondingly increased. The tendency to transfer was weaker in the SEM, which for the smooth Matrix steel resulted in very low initial friction levels. The boundary lubricant could only offer low friction in cases where the flat steel surface was smooth. The lubricant also facilitated smoothening of transferred aluminium.

The present results motivate that we repeat an important conclusion from reference [17]: for smooth sliding surfaces it is not high friction that leads to transfer but transfer that leads to high friction.

The present results also strengthen earlier observations that one of the major friction reducing effects of lubricants is to efficiently limit transfer, which otherwise acts to make the sliding surface rough. This effect is of course most important if the harder of the two sliding surfaces initially is very smooth. 
Acknowledgements The support from Swedish Research Council Grant no. 621-2013-5858 is gratefully acknowledged.

Open Access This article is distributed under the terms of the Creative Commons Attribution 4.0 International License (http://creativeco mmons.org/licenses/by/4.0/), which permits unrestricted use, distribution, and reproduction in any medium, provided you give appropriate credit to the original author(s) and the source, provide a link to the Creative Commons license, and indicate if changes were made.

\section{References}

1. Itoigawa, F., Childs, T.H.C., Nakamura, T., Belluco, W.: Effects and mechanisms in minimal quantity lubrication machining of an aluminum alloy. Wear. 260, 339-344 (2006)

2. Kelly, J., Cotterell, M.: Minimal lubrication machining of aluminium alloys. J. Mater. Process. Technol. 120, 327-334 (2002)

3. Bowden, F.P., Tabor, D.: The friction and lubrication of solids. Part 1. Clarendon Press, Oxford (1954)

4. Moghadam, M., Christiansen, P., Bay, N.: Detection of the onset of galling in strip reduction testing using acoustic emission. Procedia Eng. 183, 59-64 (2017)

5. de Rooij, M.B., van der Linde, G., Schipper, D.J.: Modelling material transfer on a single asperity scale. Wear 307, 198-208 (2013)

6. van der Heide, E., Huis, A.J., Schipper, D.J.: The effect of lubricant selection on galling in a model wear test. Wear. 251, 973-979 (2001)

7. Karlsson, P., Krakhmalev, P., Gåård, A., Bergström, J.: Influence of work material proof stress and tool steel microstructure on galling initiation and critical contact pressure. Tribol. Int. 60, 104-110 (2013)

8. Karlsson, P., Gåård, A., Krakhmalev, P.: Influence of tool steel microstructure on friction and initial material transfer. Wear 319, 12-18 (2014)
9. Podgornik, B., Hogmark, S.: Surface modification to improve friction and galling properties of forming tools. J. Mater. Process. Technol. 174, 334-341 (2006)

10. Harlin, P., Bexell, U., Olsson, M.: Influence of surface topography of arc-deposited TiN and sputter-deposited WC/C coatings on the initial material transfer tendency and friction characteristics under dry sliding contact conditions. Surf. Coat. Technol. 203, $1748-1755$ (2009)

11. Schedin, E., Lehtinen, B.: Galling mechanisms in lubricated systems: a study of sheet metal forming. Wear. 170, 119-30: (1993)

12. Chen, L.H., Rigney, D.A.: Transfer during unlubricated sliding wear of selected metal systems, Wear. 105, 47-61 (1985)

13. Menezes, P.L., Kailas, S.V., Lovell, M.R.: Tribological response of soft materials sliding against hard surface textures at various numbers of cycles. Lub. Sci. 25, 79-99 (2013)

14. Heinrichs, J., Olsson, M., Jacobson, S.: New understanding of the initiation of material transfer and transfer layer build-up in metal forming-In situ studies in the SEM. Wear 292-293, 61-73 (2012)

15. Heinrichs, J., Olsson, M., Jacobson, S.: Mechanisms of material transfer studied in situ in the SEM: Explanations o the success of DLC coated tools in aluminium forming. Wear 292-293, 49-60 (2012)

16. Heinrichs, J., Olsson, M., Jacobson, S.: Influence of tool steel microstructure on initial material transfer in metal forming-In situ studies in the SEM. Wear. 302, 1249-1256 (2013)

17. Heinrichs, J., Olsson, M., Jenei, I.Z., Jacobson, S.: Transfer of titanium in sliding contacts-New discoveries and insights revealed by in situ studies in the SEM. Wear. 315, 87-94 (2014)

18. Westlund, V., Heinrichs, J., Olsson, M., Jacobson, S.: Investigation of material transfer in sliding friction-topography or surface chemistry? Tribol. Int. 100, 213-223 (2016)

19. Kolasinski, K.W.: Surface science: foundations of catalysis and nanoscience: langmuirian adsorption. Wiley, Chichester (2002) 